\title{
Physiological and Technical-tactical Analysis in Brazilian Jiu-jitsu Competition
}

\author{
Leonardo V. Andreato*1,2ACDEG ${ }^{\text {Emerson Franchini }}{ }^{2 A C D E G}$, PhD; Solange M.F. de Moraes ${ }^{1 \mathrm{ACDEFG}}$, PhD; \\ Juliana J. Pastório ${ }^{1 B C D E}$; Danilo F. da Silva ${ }^{1 \text { BCDEG }}$; João V.D.C Esteves ${ }^{1 \text { ACDCG }}$; Braulio H.M. Branco ${ }^{1 \mathrm{BCDEFG}}$, MSc; \\ Paulo V.dS. Romero ${ }^{1 \text { BCDEG }}$; Fabiana A. Machado ${ }^{1 \mathrm{ACDEFG}}$, PhD
}

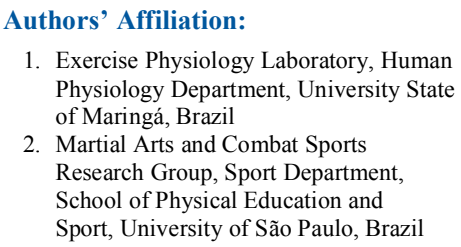

Authors' Affiliation:

1. Exercise Physiology Laboratory, Human Physiology Department, University State of Maringá, Brazil

2. Martial Arts and Combat Sports Research Group, Sport Department, School of Physical Education and Sport, University of São Paulo, Brazil

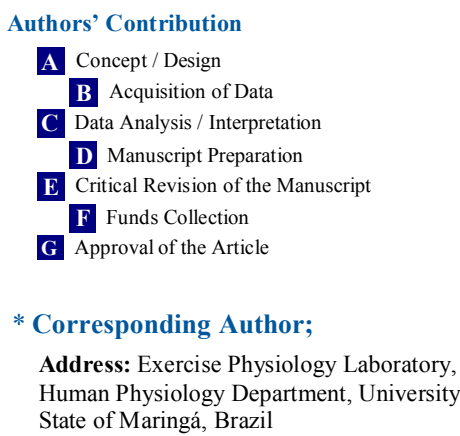

E-mail: vidal.leo@hotmail.com

Received: $\operatorname{Aug} 7,2012$

Accepted: Jan 15, 2013

Available Online: Feb 12, 2013

\begin{abstract}
Purpose: The present study aims at investigating the physiological response and technical-tactical parameters in Brazilian jiu-jitsu competition.

Methods: The study included 35 male Brazilian jiu-jitsu athletes (adult category, body mass: $80.2 \pm 13.0 \mathrm{~kg}$ ), graded from white to brown belt, during combats fought at regional level. Twenty-two fights were analyzed in terms of technique and time structure. Blood glucose, lactate and maximal isometric grip strength were determined before and after the fights. The rate of perceived exertion was also assessed after the fight, using the 6-20 Borg rating. The fights were recorded and the following variables were determined: the exertion/pause ratio and subjective intensity of actions, categorized between low and high intensity.

Results: The results indicated that during Brazilian jiu-jitsu fights, the glycolytic pathway is only moderately activated (lactate before: $4.4(4.0-4.6) \mathrm{mmol} / \mathrm{L}$, after: $10.1(8.0-11.3) \mathrm{mmol} / \mathrm{L}$; glucose before: $112.4 \pm 22.3 \mathrm{mg} / \mathrm{dL}$, after: $130.5 \pm$ $31.0 \mathrm{mg} / \mathrm{dL}$ ). The exertion during the fight resulted in significant reductions in handgrip strength (right hand grip before: $45.9 \pm 10.3 \mathrm{kgf}$, after: $40.1 \pm 9.5 \mathrm{kgf}$; left hand grip before: $44.2 \pm 11.1 \mathrm{kgf}$, after: $37.0 \pm 10.2 \mathrm{kgf})$. The athletes rated the fight as hard: $15(13-15)$. Effort/pause ratio was $6: 1$, while high-intensity actions lasted approximately $4 \mathrm{~s}$, resulting in a low/high intensity? ratio of 8:1.
\end{abstract}

Conclusions: It is recommended that coaches direct the training loads to simulate the energy demand imposed by the competitive matches, activating moderately the glycolytic pathway. Moreover, the time structure of combats can be used to prescribe both physical and technical-tactical training.

Key Words: Combat Sports; Martial Arts; jiu-jitsu; Sports; Athletic Performance

Asian Journal of Sports Medicine, Volume 4 (Number 2), June 2013, Pages: 137-143

\section{INTRODUCTION}

$\mathrm{C}$ ombat sports have gained considerable popularity ${ }^{[1]}$. Brazilian jiu-jitsu is amongst the sports that have gained most notable popularity, mainly due to the athletes' success in the mixed martial arts competitions (MMA) ${ }^{[2]}$, it has jumped to a position of prominence in the combat sport scenario.

In grappling combat sports there is an implied inability of direct measurement of exertion ${ }^{[3]}$. As such, studies on these sports have been conducted with indirect markers such as heart rate $(\mathrm{HR})^{[4]}$, blood lactate concentrations $[\mathrm{Lac}]^{[5,6]}$, rating of perceived exertion (RPE) ${ }^{[5,6]}$ or physical and anthropometric descriptions of the athletes ${ }^{[3,7,8]}$. Another helpful aid in the prescription of specific training, is the use of the time structure characteristics of fights by means of filming and the consequent determination of the effort/pause ratio ${ }^{[3,6,9,10]}$.

In Brazilian jiu-jitsu, due to observed physiological responses, such as blood lactate concentrations and the time structure of the fights, it is considered a predominantly aerobic sport with moderate activation of the glycolytic system ${ }^{[4,10,11]}$. Furthermore, an effort/ pause ratio of approximately 10:1 was found ${ }^{[10]}$, a significantly higher proportion when compared to other 
combat sports such as judo ${ }^{[12]}$ and wrestling ${ }^{[6]}$, which have presented an effort-pause ratio of approximately $2: 1$. Due to the differences in time structure, the transfer of knowledge from other combat sports to Brazilian jiu-jitsu is rather limited. Additionally, the available data concerning Brazilian jiu-jitsu is arguable, due to the low number of studies available.

Recently, Moreira et al ${ }^{[13]}$ reported lower pre-match salivary cortisol concentration in simulated compared to official Brazilian jiu-jitsu matches, suggesting that psychological factors associated with high physicalmaximize stress hormone responses. Moreover, the analysis of athletes during competition is essential in understanding the sport, since, it is believed that on these occasions athletes peak to a state of maximum exertion, this would allow for a deeper understanding of the physiological and technical-tactical demands imposed on the athletes and also allow for more adequate training stimuli for athletes to prepare for those demands. However, only this study ${ }^{[13]}$ investigated simulated and official matches and simply salivary immunoglobulin A and cortisol were measured. No study was found investigating physiological, perceptive and technical-tactical actions in Brazilian jiu-jitsu competitions. Thus, the aim of this study was to analyze the physiological, perceptive and technical-tactical parameters involved in Brazilian jiujitsu competition.

\section{METHODS AND SUBJECTS}

\section{Sample:}

The study included 35 male adult Brazilian jiu-jitsu athletes (body mass: $80.2 \pm 13.0 \mathrm{~kg}$; age: $18-30$ years), graded from white to brown belts (16 white belt, 14 blue belt, 2 purple belt and 3 brown belt). Combats were only analyzed with the consent and agreement of disputing adversaries who participated in the study. In order to allow for technical-tactical analysis, 22 fights between the participants were recorded.

All subjects were informed about the procedures of the study, and all signed informed consent forms. This study was approved by the local ethics committee. The data were collected during a Brazilian jiu-jitsu competition at regional level.

\section{Biochemical Analysis:}

Blood samples were taken approximately 2 min before the combats (after the warm-up) and immediately after fights from the earlobe for blood glucose and lactate determination, using Optium Xceed ${ }^{\circledR}$ and Accutrend ${ }^{\circledR}$ portable analyzers, respectively. Blood samples were collected in specific strips and immediately analyzed in these portable analyzers. The Optium Xceed glucose analyzer used in our study was validated via correlation with a enzymatic method (Roche Hitachi 917 System), demonstrating high correlation $(r=0.938)^{[14]}$ (Coyne et al, 2008). The reliability for this portable analyzer was reported as 0.962 via intra-class correlation ${ }^{[15]}$ (Danieletto et al, 2011). Previous study validated the lactimeter using reference methods ${ }^{[16]}$ (Fell et al, 1998) and a study from our laboratory reported a high $(\mathrm{R}=$ 0.963 ) intra-class correlation between this device and the Yellow Springs lactimeter ${ }^{[17]}$ (Franchini et al, 2004). As the data collection was conducted in a real competition setting, each athlete performed his usual warm-up procedures.

\section{Maximum Isometric Strength:}

In order to measure maximum isometric strength, athletes were submitted to the maximal handgrip strength test ${ }^{[18]}$ using a Takei Kiki Kogyo ${ }^{\circledR}$ grip dynamometer. The dynamometer was adjusted according to the size of the athletes' hand. Two non sequential attempts were made for each hand approximately $2 \mathrm{~min}$ before the fights (after warm-up), and sequential attempts were made for each hand immediately after the fights. The highest value achieved in each moment was used as the measure of handgrip strength. This approach has been used in other grappling combat sports such as judo ${ }^{[19]}$ and wrestling ${ }^{[20,21]}$, and its reliability has been reported to be high, with intra-class correlation coefficients of 0.954 and 0.912 for the left and right hands, respectively ${ }^{[22]}$. 


\section{Rate of perceived exertion:}

RPE scale (Borg 6-20) was explained (e.g. with 6 representing no fatigue and 20 representing maximal fatigue) for the athletes before the competition and at the end of the fight athletes were asked to report their $\mathrm{RPE}^{[23]}$. This scale was successfully used in some studies investigating the relationship between RPE and blood lactate concentration or heart rate after simulated and competition judo matches ${ }^{[24-26]}$.

\section{Technical-Tactical Analysis:}

The fights were recorded with the use of a Sony ${ }^{\circledR}$ (DCR-HC52) digital camera and the following variables were determined: the exertion/pause ratio and the subjective intensity of actions were categorized as low and high intensity. In order to define the effort/pause ratio, the period between the referee order to fight and pause was defined as effort and the period between the orders to pause and to restart fight was defined as pause, such as was done by Del Vecchio et al ${ }^{[10]}$ with Brazilian jiu-jitsu and Miarka et al ${ }^{[27]}$ with judo matches. Effort and pause periods were also quantified in each block of combat. A previous study from our group ${ }^{[27]}$ reported a within-evaluator reliability of 0.999 and 0.986 for combat and pause, respectively, and a between-evaluator reliability of 0.990 and 0.912 for combat and pause time, respectively.

In order to subjectively categorize the intensity of workload (low and high intensity), a high-intensity action was considered when the fighter tried to advance/progress/evolve with clear vigor, muscle strength or power, while low intensity actions were those when movements were slow and low strength seemed to be applied. It is important to remark that a tactical advance was not necessarily a high-intensity action but although it could be as effective as a vigorous action. Such analysis occurred as that conducted by Del Vecchio et al ${ }^{[9]}$ with mixed martial arts fights, but taking into consideration specific Brazilian jiu-jitsu techniques. This article ${ }^{[9]}$ reported that there was no difference between analyses conducted one week apart according to the Student $\mathrm{t}$ test comparison $(\mathrm{t}=-0.07, P=0.94)$ and the intra-class correlation coefficient was higher than 0.98 for all the variables analyzed. Although we did not test the reliability to the matches specifically analyzed in our study, our previous experience with other grappling combat sports such as judo ${ }^{[27,28]}$ and mixed martial arts [9] indicates that time-motion analysis for similar actions are highly reliable.

\section{Statistical Analysis:}

Data were processed using Excel ${ }^{\circledR}$ and SPSS 15.0 ${ }^{\circledR}$. Data are presented as mean (M), standard deviation (SD), median, percentiles (25\% and $75 \%$ ) and $95 \%$ confidence interval $(95 \% \mathrm{CI})$. Normality was accessed with the use of the Shapiro-Wilk test. Student $\mathrm{t}$ test and Wilcoxon test were used to compare moments of measure. Significance level was set in $5 \%$. To evaluate the magnitude of difference Cohen's effect size was calculated. Threshold values to effect size were $<0.2$ (small), $>0.2$ and $<0.8$ (moderate) and $>0.8$ (large) ${ }^{[29]}$.

\section{RESULTS}

Table 1 presents glucose $(\mathrm{mg} / \mathrm{dL})$, lactate $(\mathrm{mmol} / \mathrm{L})$, handgrip (kgf) and RPE (6-20) values at pre and post Brazilian jiu-jitsu fights.

Table 1: Biochemical and physiological parameters before and after the Brazilian Jiu-jitsu fights

\begin{tabular}{|c|c|c|c|c|}
\hline \multirow{2}{*}{ Parameters } & \multicolumn{2}{|c|}{ Before } & \multicolumn{2}{|c|}{ After } \\
\hline & Mean \pm SD & $95 \% \mathrm{CI}$ & Mean \pm SD & $95 \% \mathrm{CI}$ \\
\hline Glucose (mg/dL) & $112.4(22.3)$ & $105.5-119.3$ & $130.5(24.2)^{*}$ & $123.0-137.9$ \\
\hline Lactate $(\mathrm{mmol} / \mathrm{L})^{\mathrm{a}}$ & $4.4(4.0-4.6)$ & $4.2-4.9$ & $10.1(8.0-11.3)^{*}$ & $8.4-10.2$ \\
\hline Right Hand Grip (kgf) & $45.9(10.3)$ & $42.7-49.0$ & $40.1(9.5)^{*}$ & $37.2-43.0$ \\
\hline Left Hand Grip (kgf) & $44.2(11.1)$ & $40.8-47.6$ & $37.0(10.2)^{*}$ & $33.9-40.1$ \\
\hline Rating of Perceived Exertion (6-20) ${ }^{a}$ & - & - & $15(13-15)$ & $14-15$ \\
\hline
\end{tabular}


Table 2: Technical-tactical analysis in Brazilian jiu-jitsu fights ( $\mathrm{n}=22$ matches)

\begin{tabular}{lcc} 
Parameters & Mean \pm SD & CI 95\% \\
\hline Total time of effort (s) & $296(170-349)^{\text {a }}$ & $218-309$ \\
Average time of effort per block (s) & $117(65-150)^{\text {a }}$ & $91-161$ \\
Effort blocks & $2(2-3)^{\ddagger}$ & $2-3$ \\
Total time of pause (s) & $33(25)$ & $22-44$ \\
Average time of pause per block (s) & $20(14)$ & $14-26$ \\
Pause blocks & $1(1-2)^{\text {a }}$ & $1-2$ \\
Total time of effort at high-intensity (s) & $24(14)$ & $18-30$ \\
Average time of effort at high-intensity per block (s) & $3(2-4)^{\text {a }}$ & $2-5$ \\
High-intensity blocks & $8(3)$ & $7-10$ \\
Total time of effort at low-intensity (s) & $249(149-297)^{\text {a }}$ & $182-265$ \\
Average time of effort at low-intensity per block (s) & $25(9)$ & $21-29$ \\
Low-intensity blocks & $9(3)$ & $8-11$ \\
a non normal distribution $(P<0.05)$, data are expressed as median and percentiles $(25 \%$ and $75 \%)$ &
\end{tabular}

As a result of the combats, there was an increase in the glucose concentrations (pre vs post, $\mathrm{t}=4.3, P<0.001$, $\mathrm{df}=42$, es $=0.78$ ) and blood lactate (pre vs. post, $\mathrm{W}=$ 638.0, $P<0.001, \mathrm{df}=37$, es=2.31), and a significant drop in values registered for maximum isometric strength of the right handgrip (pre vs. post, $\mathrm{t}=4.9, P<0.001, \mathrm{df}=43$, es $=-0.59$ ) and the left handgrip (pre vs. post, $\mathrm{t}=5.5$, $P<0.001, \mathrm{df}=43$, es $=-0.68$ ). The RPE reported by the athletes after the fight is classified as strenuous ${ }^{[23]}$.

Technical-tactical variables during the 22 fights performed by the athletes are presented on Table 2 .

Effort/pause ratio was $6: 1$, while high-intensity actions lasted 2-5 s, resulting in a low/high-intensity ratio of $8: 1$.

\section{DISCUSSION}

The aim of the present study was to analyze the physiological and technical-tactical parameters involved in Brazilian jiu-jitsu fights. The results indicated a moderate activation of the glycolytic system and a significant drop in handgrip strength as a consequence of the fights. Furthermore, the athletes classified the exertion as strenuous. A 6:1 effort/pause ratio was identified, with short $(\sim 3 s)$ high-intensity actions. These characteristics can help coaches to improve their training prescription to Brazilian jiu-jitsu athletes.
The measurements of blood lactate concentration after fights indicated a moderate activation of the glycolytic pathway ${ }^{[11,30,31]}$, which can be reinforced by the significant increase in glucose plasma during the fight. Other studies also noted an increase in lactate and glucose in similar sports such as wrestling [20,21] and judo ${ }^{[32,33]}$. The lactate concentrations shown in this study were similar to those of other studies on highlevel Brazilian jiu-jitsu athletes $(n=7,10.2 \pm 1.5$ mmol/L two minutes after the end of the fight ${ }^{[10]}$, as well as with black belt athletes after a fight simulation $(\mathrm{n}=8,9.5 \pm 2.4 \mathrm{mmol} / \mathrm{L})^{[5]}$. Studies carried out with judo athletes have pointed out similar measurements after the fight ${ }^{[3]}$, however, lactate concentrations have been greater after wrestling matches ${ }^{[21,21]}$. Thus, it can be suggested that a large part of the lactate formed probably originated from the glucose released by the degradation of muscular glycogen.

However, the plasma lactate concentration does not reflect only its production in the muscle, but also its conversion into glucose, since a significant proportion of lactate is converted to glucose in the liver through gluconeogenesis that could have played a role in the maintenance of blood glucose ${ }^{[34]}$ and may have contributed to increased glucose concentration.

Furthermore, the lactate increase may have occurred by a possibly greater adrenergic activity which induces hepatic glycogenolysis, as well as by a greater gluconeogenic activity mediated by glucagon, since such events occur in high-intensity activities ${ }^{[34,35]}$. 
The significant activation of the glycolytic pathway can be explained by the effort/pause ratio of 6:1 (effort: $117 \mathrm{~s}(65-150 \mathrm{~s})$, pause: $20 \pm 14 \mathrm{~s})$ noted in this study, since the brief periods of pause are insufficient to fully restore the phosphagen system ${ }^{[36]}$. These time structure results are similar to those described by Del Vecchio et al ${ }^{[10]}$ on analysis of 33 fights at the Brazilian jiu-jitsu World Cup in 2005, where the authors noted that the matches consisted of $170 \mathrm{~s}$ of fighting (fight on the ground: $146 \pm 119 \mathrm{~s}$; fight standing: $25 \pm 17 \mathrm{~s}$ ) for $13 \pm$ $6 \mathrm{~s}$ recovery. Thereby, it becomes evident that the time structure of a Brazilian jiu-jitsu fight is different from other grappling combat sports, considering that in judo, the time structure of fights is $30 \pm 33 \mathrm{~s}$ of fighting for a $11 \pm 10$ s pause ${ }^{[37]}$ while in wrestling it is $37 \pm 10 \mathrm{~s}$ of fighting for a $14 \pm 6$ s pause ${ }^{[6]}$.

However, caution should be exercised on interpreting the exertion/pause ratio in combat sports, since it is possible to erroneously consider the entire period of exertion as being composed by high-intensity actions. The subjectively partitioning of the exertion period into high and low-intensity actions can provide valuable indicatives to a greater understanding of combat dynamics and application to training ${ }^{[9]}$. In this regard, on categorizing exertion as to its intensity, it is noted that high-intensity activities were revealed to be of very short duration. Given this information, the importance of the development of the phosphocreatine system and the short period for resynthesis of its substrates becomes relevant for performance improvement in this sport.

Concurrently, in moments of low-intensity actions, it is possible to verify the isometric strength demand, another characteristic of Brazilian jiu-jitsu, due to the constant contact between opponents ${ }^{[8]}$. Such a statement can be reinforced by the fact that the athletes who participated in this study revealed a significant drop in handgrip strength during the course of fights.

Concerning handgrip strength, two aspects are worthy of mention: firstly, the maximum isometric strength does not seem to be an important characteristic in Brazilian jiu-jitsu, as noticed previously, due to the fact that athletes who practice this sport, do not reveal substantial handgrip strength ${ }^{[4,8,10,38]}$, although the athletes are able to maintain a high percentage of their maximum isometric handgrip strength until the end of the fight ${ }^{[4]}$. Despite the variation in pre and post fight values noted in this study, the average decline in strength was approximately $11 \%$ and $16 \%$ for the right and left hands, respectively. Franchini et al ${ }^{[4]}$ identified a similar strength maintenance, reporting a decline of approximately $15 \%$ after a five minute Brazilian jiujitsu combat simulation.

Another indicator of exertion and means of controlling the training load, of easy access, application and low cost, which has often been used in the past few years, is the scale of RPE ${ }^{[23]}$. In this study, the values obtained for RPE indicate that athletes perceive the fight as hard. These values are similar to those registered by Franchini et al ${ }^{[5]}$ in a study with black belt Brazilian jiu-jitsu athletes who were submitted to 10 minute duration simulated fights $(\mathrm{n}=8,13 \pm 14)$, as well as those registered by Nilsson et al ${ }^{[6]}$ with wrestling athletes during the 1998 World Championship (14 \pm 3$)$. Although the pause periods in Brazilian jiu-jitsu fights are insufficient to allow for the complete resynthesis of phosphocreatine and only moderately activate the glycolytic system, it is believed that RPE was inferior to the concomitant increase of the lactate concentrations, due to the fact that, in Brazilian jiu-jitsu, muscular groups alternate a lot during the fight which could influence the RPE to be generally low.

Besides that, the lactate accumulated and the hydrogen ions associated with this metabolite are probably formed within small muscle groups such as the forearm and shoulder ${ }^{[5]}$, thus causing little disturbance in the general RPE. Concurrently, Marcora et $\mathrm{al}^{\left[{ }^{[39]}\right.}$ states that the presence of sensory mechanisms and a high correlation between metabolic stimuli and perceived exertion does not necessarily suggest that these are related. Furthermore, it was proposed that RPE does not necessarily depend on feedback originating from afferent information of the muscular and cardio-vascular systems ${ }^{[40]}$.

Thereby, perception of exertion originates from stimuli as a consequence of motor impulses, in the form of an efferent copy from the cortex to the sensorial motor ${ }^{[41]}$. Therefore, RPE could have been inferior to the increase of lactate concentrations because it does not depend on afferent feedback to the sensory cortex. Furthermore, it has been suggested that 
athletes could perceive the same physiological stimulus in different forms as a consequence of their individual psychological state ${ }^{[42]}$. Another factor which has been suggested as an explanation for the relatively low values of subjective perception of exertion during combat sports is the directing of attention to the opponents actions and the external sensory stimuli (e.g. decision making, sound stimuli) ${ }^{[43]}$.

However, it is important to take into consideration that the conclusions of this study are limited to Brazilian jiu-jitsu competitions at regional level, although some athletes in our sample have been national and/or international medalists, and that the majority was low grade (white and blue belt) athletes. Therefore, new studies analyzing higher level competitions and with athletes of varied technical level, should be done in order to allow for a greater understanding of this combat sport. In fact, it is important to consider that the conclusions of this study are limited by the heterogeneity of graduation of the athletes. Thus, new studies should aim to identify whether there are differences between groups from different grades.

\section{Practical Applications}

Based on results obtained in this study, it is recommended that coaches impose training loads that simulate the energy demand imposed by the combats, activating moderately the glycolytic pathway. The time structure of combats can be used to prescribe both physical and technical-tactical training. Therefore, the execution of successive combats with short period of recovery, something usually experienced in Brazilian jiu-jitsu training sessions, should not be prioritized. Conversely, in the competitive period high-intensity combat could be prioritized, considering official competition duration, and intervals between fights similar to those established in competitions or long enough to provide full recovery for athletes.

The physiological measurements provided evidence that muscle glycogen was used during the official match, because it was observed an increase in glucose and blood lactate concentrations. Therefore, nutritional strategies that meet the supply of glucose during the competition could be used to provide adequate intake of carbohydrates before competitions and specific training sessions.

The activity performed during the match resulted in significant reductions in handgrip strength. Thus, the grip strength endurance should be worked out during training sessions (e.g. adding exercises with kimono that involve lift or grip) to help the athlete to improve his strength maintenance during the competition match.

The high-intensity actions performed were predominantly short (i.e. less than $3 \mathrm{~s}$ ). Consequently, muscle power exercises should also be included in physical training, since the decisive moments of the fight (scores and submissions) require high muscle power actions.

Furthermore, the use of RPE should be viewed with caution to control the intensity of Brazilian jiu-jitsu fights, as the muscle groups' alternation during the fight and the direction of the athlete's attention to the actions of his opponent can change the relationship between exercise intensity and the RPE of these athletes.

\section{CONCLUSION}

The results of the present study indicate that during Brazilian jiu-jitsu fights the glycolytic pathway is moderately activated. However, the large amount of interchange between muscular groups during a fight could have influenced the athletes to consider the fight as only hard. Moreover, the attention directed at the opponents actions could also have influenced the low values registered for RPE. Furthermore, actions in the course of the fight resulted in a significant reduction of handgrip strength. The effort/pause ratio was $8: 1$, while high-intensity actions lasted approximately $3 \mathrm{~s}$, resulting in a low/high-intensity ratio of $8: 1$. This time structure can be used to prescribe both physical and technical-tactical training.

\section{ACKNOWLEDGMENTS}

The authors thank to Eloa Jacques Pastório and Lucas Kazunori Rubira Babata for their assistance with data collection. This study was supported by CNPq (471201/2012-0).

Conflict of interests: None 


\section{REFERENCES}

[1] Franchini E, Nunes AV, Moraes JM, Del Vecchio FB. Physical fitness and anthropometrical profile of the Brazilian male judo team. $J$ Physiol Anthropol 2007;26:59-67.

[2] Gracie R, Gracie C. Brazilian Jiu-Jitsu: Theory and Technique. With Kid Peligro. Invisible Cities Press. Montpelier, Vermon. 2000.

[3] Franchini E, Matsushigue KA, Vecchio FB, Artioli GG. Physiological profiles of elite judo athletes. Sports Med 2011;41:147-66.

[4] Franchini E, Takito MY, Pereira JNDC. Freqüência cardíaca e força de preensão manual durante a luta de jiu-jitsu. Lecturas Educación Física y Deportes 9(65), 2003. Available at: http:// efdeportes.com/efd65/jiujitsu.htm. Access date: Jun 30, 2012.

[5] Franchini E, Bezerra PL, Oliveira RSF, et al. Concentração de lactato sanguíneo, frequência cardíaca e força de preensão manual durante um combate de jiu-jitsu. Corpoconsciência 2005;9:35-44.

[6] Nilsson J, Csergö S, Gullstrand L, et al. Work-time profile, blood lactate concentration and rating of perceived exertion in the 1998 Greco-Roman Wrestling World Championship. J Sports Sci 2002;20:939-945.

[7] Andreato LV, Franchini E, Franzói de Moraes SM, et al. Perfil morfológico de atletas de elite de Brazilian Jiu-jitsu. Rev Bras Med Esporte 2012;18:47-51.

[8] Vidal Andreato L, Franzói de Moraes SM, Lopes de Moraes Gomes T, et al. Estimated aerobic power, muscular strength and flexibility in elite Brazilian Jiu-jitsu athletes. Sci Sports 2011;26:329-37.

[9] Del Vecchio FB, Hirata SM, Franchini E. A review of time-motion analysis and combat development in Mixed Martial Arts matches at regional level tournaments. Percept Mot Skills 2011;112:1-10.

[10] Del Vecchio FB, Bianchi S, Hirata SM, Chacon-Mikahili MPT. Análise morfo-funcional de praticantes de Brazilian jiu-jitsu e estudo da temporalidade e da quantificação das ações motoras na modalidade. Movimento e Percepção 2007;7:263-81.

[11] Andreato LV, Franzói de Moraes SM, Esteves JVDC, et al. Physiological responses and rate of perceived exertion in Brazilian jiu-jitsu athletes. Kinesiology 2012;44:173-81.

[12] Casterlanas JL, Planas A. Estudio de la estrutura temporal del combate de judo. Apunts 1997;1:32-39.

[13] Moreira A, Franchini E, Freitas CG, et al. Salivary cortisol and immunoglobulin A responses to simulated and official jiu-jitsu matches. $J$ Strength Cond Res 2012;26:2185-91.

[14] Coyne S, Lacour B, Hennequin-Le Meur C. [Evaluation of Optium Xceed (Abbott) and One Touch Ultra (Lifescan) glucose meters]. Ann Biol Clin 2008;66:249-254.

[15] Danieletto CF, Cordeiro RF, Iwaki LCV, et al. Análise Comparativa entre Aparelhos de Pressão Arterial e entre Glicosímetros de Diferentes Marcas na Detecção de Pacientes Hipertensos e Diabéticos. Pesq Bras Odontoped Clin Integr 2011;11:525-31.

[16] Fell JW, Rayfield JM, Gulbin JP, Gaffney PT. Evaluation of the Accusport ${ }^{\circledR}$ lactate analyser. Int J Sports Med 1998;19:199-204.

[17] Franchini E, Matsushigue KA, Colantonio E, Kiss MAPDM. Comparação dos analisadores de lactato Accusport e Yellow Springs. $R$. bras Ci e Mov 2004;12:39-43.

[18] Johnson BL, Nelson JK. Practical Measurements for Evaluation in Physical Educatión. Minnesota: Burgess Publishing Company, 1979.

[19] Bonitch-Góngora JG, Bonitch-Domínguez JG, Padial P, Feriche B. The effect of lactate concentration on the handgrip strength during judo bouts. $J$ Strength Cond Res 2012;26:1863-71.

[20] Barbas I, Fatouros IG, Douroudos II, et al. Physiological and performance adaptations of elite Greco-Roman wrestlers during a one-day tournament. Eur J Appl Physiol 2011;111:1421-1436.

[21] Kraemer WJ, Fry AC, Rubin MR, et al. Physiological and performance responses to tournament wrestling. Med Sci Sports Exerc 2001;33:1367-78.

[22] Bohannon RW, Schaubert KL. Test-retest reliability of grip-strength measures obtained over a 12-week interval from communitydwelling elders. $J$ Hand Ther 2005; 18:426-427.

[23] Borg GAV. Psychophysical bases of perceived exertion. Med Sci Sports Exerc 1982;14:377-381.

[24] Franchini E, Takito MY, Lima JRP, et al. Características fisiológicas em testes laboratoriais e resposta da concentração de lactato sanguíneo em 3 lutas em judocas das classes Juvenil-A, Júnior e Sênior. Rev Paul Educ Fis 1998;12:5-16.

[25] Serrano M A, Salvador A, Gonzalez-Bono E, et al Relationships between recall of perceived exertion and blood lactate concentration in a judo competition. Percept Mot Skills. 2001;92:1139-1148.

[26] Bonitch J, Ramirez J, Femia P, et al. Validating the relation between heart rate and perceived exertion in a judo competition. Medicina dello Sport 2005;58:23-28.

[27] Miarka B, Hayashida C, Julio UF, et al. Objectivity of FRAMI-Software for Judo Match Analysis. Int J Perform Anal Sport 2011;11: 254-66.

[28] Miarka, B, Panissa, VLG, Julio, UF, et al A comparison of time-motion performance between age groups in judo matches, J Sports Sci. 2012;30:899-905.

[29] Cohen J. Statistical power analysis for the behavioral sciences. Hillsdale, Lawrence Erlbaum, 1988.

[30] Di Prampero PE, Ferretti G. The energetics of anaerobic muscle metabolism: a reappraisal of folder and recent concepts. Respir Physiol. 1999;118:103-115.

[31] Rusko HK, Nummela A. Measurement of maximal and submaximal anaerobic performance capacity: concluding chapter. Int $J$ Sports Med. 1996;17:S125-9.

[32] Degoutte F, Jouanel P, Filaire E. Energy demands during a judo match and recovery. Br J Sports Med. 2003;37:245-49.

[33] Franchini E, Bertuzzi RCM, Takito MY, Kiss MA. Effects of recovery type after a judo match on blood lactate and performance in specific and non-specific judo tasks. Eur J Appl Physiol. 2009;107: 377-383. 